\title{
STUDY OF REMOBILIZATION OF WINTER BREAD WHEAT (TRITICUM AESTIVUM L.) UNDER RAINFED CONDITIONS
}

\author{
JAHANGirov, A. A. ${ }^{1}$ - AllahVERdiyeV, T. I. ${ }^{2,3^{*}}-$ TAlAI, J. M. ${ }^{2}$ - HuSEYNOVA, I. M. ${ }^{3}$ \\ ${ }^{1}$ Gobustan Experimental Station of Research Institute of Crop Husbandry \\ Gobustan AZ 3700, Azerbaijan \\ ${ }^{2}$ Research Institute of Crop Husbandry, Ministry of Agriculture of the Republic of Azerbaijan \\ Pirshagy village, Sovkhoz 2, Baku AZ 1098, Azerbaijan \\ ${ }^{3}$ Institute of Molecular Biology and Biotechnology, Azerbaijan National Academy of Sciences \\ 2 A Matbuat Avenue, Baku AZ 1073, Azerbaijan \\ *Corresponding author \\ e-mail: tofig_1968@mail.ru; phone: +994-50-463-1989 \\ (Received $17^{\text {th }}$ Feb 2019; accepted $8^{\text {th }}$ Apr 2019)
}

\begin{abstract}
Remobilization coefficient of 21 winter bread wheat genotypes has been studied under rainfed conditions during two growing seasons with contrasting climate of Mountainous Shirvan district of Azerbaijan Republic. Remobilization coefficient was found to be higher in the year of drought compared to the year with normal precipitation. Remobilization coefficient of short and medium height genotypes was higher than that of tall genotypes, which indicates a negative correlation between plant height and remobilization coefficient. However, this correlation was not observed in the year with severe drought stress.
\end{abstract}

Keywords: bread wheat, remobilization coefficient, drought, plant height, grain yield

\section{Introduction}

As all living organisms, plants are also exposed to the effects of adverse environmental factors. Under the influence of these factors, stress or state of the "tension", providing the universal protective reaction during growth, is created. The existence of the "echeloned defense" system provides a necessary tolerance for plant organisms and it is a main condition for the protection of species. Currently, intensive efforts have been made for studying stress mechanisms at molecular-genetic and cellular levels (Mwadzingeni et al., 2016; Gupta et al., 2017). Response of plants to stresses changes depending on plant species and genotype, duration and intensity of water deficiency, plant age and growth phase, plant organ and cell type, and at last cell compartmentalization (Zhu, 2002; Rampino et al., 2006). A high ability of the plant to change its metabolism according to the environment leads to a high reaction norm for this plant, which is a distinctive trait for tolerant plant varieties (Moussa and AbdelAziz, 2008).

Various stresses cause a decline in the productivity of agricultural plants. Considering the possibility of future difficulties in the meet of the demand of population in food products, one of the main tasks is developing new productive and tolerant varieties using genotypes tolerant to stress factors-adverse soil and climatic conditions, drought, high temperature, salinity etc. (Aliyev, 2012). Water restriction is main factor that limiting plant growth. 
Wheat (Triticum aestivum L.) is one of the main crops in human nutrition. Adverse biotic and abiotic stresses negatively affect the productivity of wheat, do not allow the realization of genetic potential (Allahverdiyev et al., 2018). The forming of winter wheat yield depends on the factors affecting plants during a long vegetation period. Annual precipitation and air temperature are very important ecological factors affecting plant productivity. From this point of view developing drought tolerant varieties is of great importance. Therefore, new methods considering physiological properties of plants are to be used along with classical methods.

The process of remobilization has also a great role in the formation of grain yield of wheat plants under drought. Remobilization is a process of the use of compounds, which had been synthesized prior to the reproductive phase and preserved as resources in the stem, at the stages of grain formation and grain filling. Kalayci et al. (1998) argued that remobilization in wheat genotypes is of great importance only when drought is imposed at the grain filling stage. According to Blum and Pnuel (1998) remobilization has no effect on productivity when drought stress is imposed at the tillering stage, plants are not exposed to stress at the grain filling stage and productivity is about 1.78 ton/ha. Yang et al. (2002) reported high variation among genotypes for relative contribution of photosynthesis and stem reserves in wheat grain yield under the heat stress condition. Some genotypes tolerated the heat stress by preserving the stable photosynthesis and some others via the stem reserves. During grain filling, most of assimilates translocated to grains are provided by current photosynthesis in flag, penultimate leaves and spike (Arduini et al., 2006). A substantial part of grain dry matter can originate from remobilization of assimilates accumulated until anthesis and deposited temporarily in different vegetative parts of plants (Dordas, 2012).

Some authors showed that remobilization was more important during ear filling in cases of weakened photosynthesis, when soluble carbohydrates accumulated earlier in stem were transported to grain, because more carbohydrates were accumulated in tall and thick stems (Reynolds et al., 1999).

It was also shown that as leaf yellowing and plant drying processes proceed very fast at high temperatures, because of the short period between the start of yellowing and maturing, less dry matter can be accumulated in grain by remobilization (Zamani et al., 2014). Thus, the study of remobilization is suggested to be very important for developing wheat genotypes with more stable productivity under drought conditions. The presented research is devoted to the study of remobilization in winter wheat under dry rainfed conditions.

\section{Materials and methods}

\section{Plant material and growth conditions}

The present studies were performed in the field of Gobustan Experimental Station, Research Institute of Crop Husbandry, Azerbaijan. Twelve winter bread wheat varieties and nine stable lines selected for rainfed regions were used in the experiments. The experiments were conducted during the 2012-2013 and 2013-2014 growing seasons under dry rainfed conditions of Mountainous Shirvan district. Each genotype was grown in $1 \mathrm{~m}^{2}$ areas with three replications according to randomized block design. Sowing was done at an average density 400 seeds $\times \mathrm{m}^{-2}$. The cultivated area is at an altitude of 780 $\mathrm{m}$ above sea level and it is light chestnut type, medium carbonate soil. According to the 
perennial data, the amount of annual atmospheric precipitation in the region is $350-400$ $\mathrm{mm}$. Precipitation occurs mainly during autumn-winter periods.

\section{Treatment}

Sprinkling was performed with 4\% magnesium chlorate $\left(\mathrm{Mg}\left(\mathrm{ClO}_{3}\right)_{2}\right)$ on 20-25 days after earing in order to dry green parts of the plant. Prior to the sprinkling ear samples were taken. Two days after the sprinkling, plants began to dry. After the complete maturation, samples were taken from unsprinkled area for control and 10 ears were taken from the sprinkled area. The ear samples were kept at $85^{\circ} \mathrm{C}$ for $24 \mathrm{~h}$ in the dryer, then grains were detached from ears, weighed and the weight of one grain was calculated. Coefficient of remobilization was calculated according to the formula (Kalayci et al., 1998): CR = (WGS - WGB) $/(\mathrm{CW}-\mathrm{WGB}) \times 100 \%$, where: CR coefficient of remobilization, WGS - weight of one grain from the sprinkled area (mg), WGB - weight of one grain before sprinkling $(\mathrm{mg}), \mathrm{CW}$ - weight of one grain from the control area (mg).

Statistical analyses were performed by SPSS 16 software.

\section{Results and discussion}

The monthly rainfall and average temperatures during the wheat vegetation period (September-June) for the two growing seasons and average perennial (1984-2014) shown in Table 1 were provided by the Gobustan Hydrometeorological Station. As seen in the table amount of the precipitation during the 2012-2013 growing season was $337.7 \mathrm{~mm}$, and during the 2013-2014 growing season it significantly decreased to $222.3 \mathrm{~mm}$. Air temperature also varied during the years of the study. Thus, in 20122013 air temperature was in average perennial limits, but in the spring months of the 2013-2104 growing season air temperature was above average perennial values. The mentioned changes in weather conditions affected the remobilization process in winter bread wheat.

Table 1. Weather conditions during the two growing seasons and average perennial

\begin{tabular}{c|c|c|c|c|c|c}
\hline \multirow{2}{*}{ Months } & \multicolumn{2}{|c|}{$\mathbf{2 0 1 2 - 2 0 1 3}$} & \multicolumn{2}{c|}{$\mathbf{2 0 1 3 - 2 0 1 4}$} & \multicolumn{2}{c}{ Average perennial } \\
\cline { 2 - 7 } & $\begin{array}{c}\text { Precipitation } \\
(\mathbf{m m})\end{array}$ & $\begin{array}{c}\text { Average temp. } \\
\left({ }^{\circ} \mathbf{C}\right)\end{array}$ & $\begin{array}{c}\text { Precipitation } \\
(\mathbf{m m})\end{array}$ & $\begin{array}{c}\text { Average temp. } \\
\left({ }^{\circ} \mathbf{C}\right)\end{array}$ & $\begin{array}{c}\text { Precipitation } \\
(\mathbf{m m})\end{array}$ & $\begin{array}{c}\text { Average temp. } \\
\left({ }^{\circ} \mathbf{C}\right)\end{array}$ \\
\hline September & 23.1 & 18.0 & 52.0 & 19.5 & 31.0 & 17.1 \\
October & 24.1 & 14.9 & 23.2 & 11.2 & 45.0 & 11.2 \\
November & 21.6 & 7.8 & 11.7 & 7.2 & 36.0 & 6.0 \\
December & 28.7 & 2.2 & 18.3 & -0.7 & 30.0 & 1.7 \\
January & 27.5 & 1.0 & 20.1 & 0.03 & 26.0 & -0.2 \\
February & 48.2 & 3.2 & 12.5 & -0.23 & 35.0 & 0.1 \\
March & 28.9 & 6.2 & 37.4 & 4.9 & 42.0 & 3.1 \\
April & 40.2 & 9.7 & 19.8 & 10.7 & 47.0 & 9.2 \\
May & 75.2 & 15.7 & 23.2 & 19.5 & 47.0 & 14.9 \\
June & 20.2 & 20.9 & 4.1 & 21.1 & 40.0 & 19.5 \\
\hline Total & $\mathbf{3 3 7 . 7}$ & & $\mathbf{2 2 2 . 3}$ & & $\mathbf{3 7 9 . 0}$ & \\
Average & & $\mathbf{9 . 9 6}$ & & $\mathbf{9 . 3 2}$ & & $\mathbf{8 . 3}$ \\
\hline
\end{tabular}


The remobilization coefficient of the studied genotypes is presented in Table 2. As seen in the table in 2013 the average remobilization coefficient of all studied genotypes was $13.2 \%$. In 2014 this value significantly increased to $21.4 \%$. Low values of the remobilization coefficient in the 2012-2013 and high values in the 2013-2014 growing seasons are attributed to favorable and unfavorable weather conditions of these years, respectively.

Table 2. Coefficient of remobilization (\%) of the studied genotypes

\begin{tabular}{|c|c|c|c|c|}
\hline \multirow{2}{*}{ Number } & \multirow{2}{*}{ Genotypes } & \multicolumn{2}{|c|}{ Years } & \multirow{2}{*}{ Average } \\
\hline & & 2013 & 2014 & \\
\hline 1 & Bezostaya 1 & 8.7 & 22.5 & 15.6 \\
\hline 2 & Gyzyl bugda & 7.3 & 23.3 & 15.3 \\
\hline 3 & Sheki 1 & 9.2 & 23.6 & 16.4 \\
\hline 4 & Sonmez & 8.5 & 25.8 & 17.2 \\
\hline 5 & Aran & 15.1 & 20.2 & 17.7 \\
\hline 6 & Vostorg & 17.0 & 25.7 & 21.4 \\
\hline 7 & Murov 2 & 17.1 & 27.8 & 22.5 \\
\hline 8 & Gobustan & 11.2 & 21.4 & 16.3 \\
\hline 9 & Tale 38 & 13.9 & 19.3 & 16.6 \\
\hline 10 & Fatime & 12.2 & 10.9 & 11.6 \\
\hline 11 & Gyrmyzy gul 1 & 17.3 & 28.7 & 23.0 \\
\hline 12 & Zirve 85 & 14.5 & 19.2 & 16.9 \\
\hline 13 & 7WON-SA № 465 & 13.9 & 15.1 & 14.5 \\
\hline 14 & FERRIGINEUM 2/19 & 13.5 & 15.9 & 14.7 \\
\hline 15 & 11 IWWYT№ 20 & 14.6 & 20.2 & 17.4 \\
\hline 16 & 12 IWWYT № 6 & 14.3 & 23.1 & 18.7 \\
\hline 17 & 12 IWWYT № 8 & 14.3 & 15.2 & 14.8 \\
\hline 18 & 12 IWWYT № 9 & 11.6 & 16.3 & 14.0 \\
\hline 19 & 12 IWWYT № 17 & 11.3 & 30.4 & 20.9 \\
\hline 20 & 7 WON-SA № 477 & 16.3 & 20.3 & 18.3 \\
\hline 21 & 4 th FEFWSN № 50 & 15.1 & 25.5 & 20.3 \\
\hline & Average & 13.2 & 21.4 & 17.3 \\
\hline
\end{tabular}

In 2013 the remobilization coefficients of the Gyrmyzy gul 1, Murov 2, Vostorg and Aran varieties were found to be higher compared with other studied varieties. This may be due to the late maturation of the varieties, except Murov 2, thus, the ear filling stage of these varieties occurred under high temperature and drought period. There were also reports on late maturing varieties, which remobilization coefficients were higher due to drought and high temperature (Chekich, 2007). Higher remobilization coefficient of Murov 2 compared with other genotypes is probably related to individual biological properties of this genotype. It should be noted that the remobilization coefficients of the Vostorg and Gyrmyzy gul 1 varieties were also higher in 2014. There were reports on the existence of a positive correlation between productivity and remobilization coefficient during drought years (Kalayci et al., 1998; Chekich, 2007). However, we did not observe a significant relation between the remobilization coefficient and 
productivity during favorable 2013 year and unfavorable 2014 drought year. We suggest that remobilization was not very important for the productivity under favorable weather conditions of 2013.

In 2014 remobilization coefficient increased in all genotypes because of severe drought and temperature stress. However, the period between the beginning of leaf yellowing and maturing was very short and other factors appeared to be more important for productivity than remobilization. As a result, in spite of the higher remobilization coefficient during the drought year, there was no correlation between productivity and remobilization coefficient. Moreover, different remobilization coefficients were found for the genotypes during the unfavorable year with higher values for Sonmez, Vostorg, Murov 2, Gyrmyzy gul 1 and $12^{\text {th }}$ IWWYT№17. There was no significant relation between grain yield and water soluble carbohydrate remobilization under heat stress during grain filling (Zamani et al., 2014). Grain yield exhibited a low positive correlation with water soluble carbohydrates at anthesis under water stress (Del Pozo et al., 2016).

In 2012-2013 growing season we detected a negative correlation (Fig. 1) between the remobilization coefficient and plant height with $\mathrm{R}^{2}=0.38^{* *}$ (reliability within 0.01 ), while there was no correlation between the remobilization coefficient and the length of peduncle. However, in 2014 we observed the absence of the correlation between remobilization coefficient and both mentioned parameters, which could be attributed to severe drought and high temperatures.

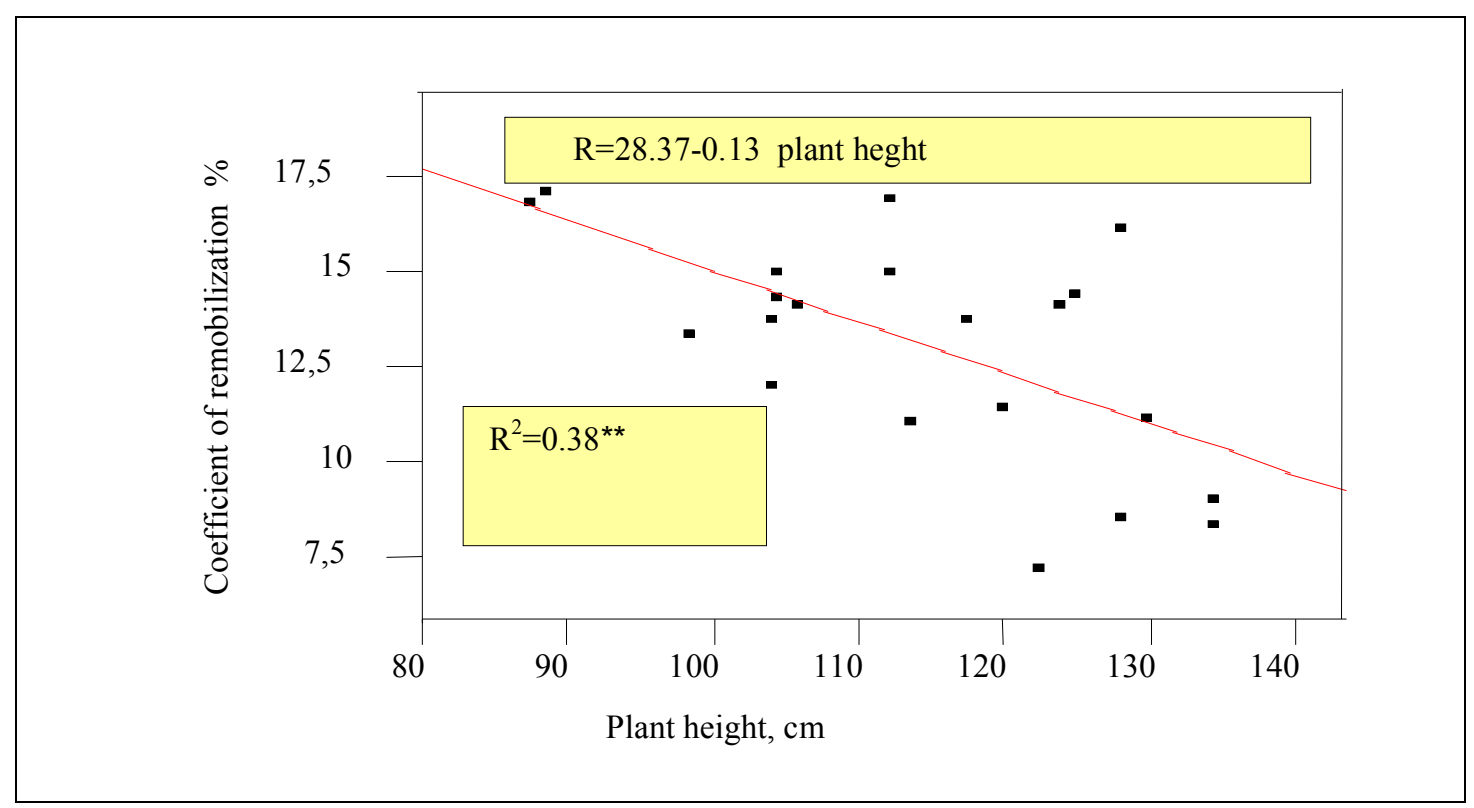

Figure 1. Interrelation between the plant height and remobilization coefficient in the 2012-2013 growing season

We suggest that the reason of the low values of remobilization coefficient for the varieties Bezostaya 1, Gyzyl bugda, Shaki 1 and Sonmez is the tallness of these varieties. As assimilates should pass very long distance to be transported to grain.

The high values of the remobilization coefficient in the Gyrmyzy gul 1, Vostorg and other genotypes can be attributed to their late maturation and short stature. Analogical 
results were obtained in the previous experiments conducted with radioactive $\mathrm{C}$ atoms (Jahangirov, 1987).

\section{Conclusion}

Thus, the study of remobilization in winter bread wheat genotypes under dry rainfed conditions of Mountainous Shirvan region showed that this parameter was dependent on weather conditions and individual biological properties of the genotypes. Remobilization coefficient was found to be higher during drought years. It was also established that remobilization coefficient was higher in short and medium-height genotypes compared with tall genotypes, which indicate a negative correlation between the remobilization coefficient and plant height.

Acknowledgments. Authors are thankful to Gobustan Hydrometeorological Station for providing information on annual and perennial precipitation and temperature.

\section{REFERENCES}

[1] Aliyev, J. A. (2012): Photosynthesis, photorespiration and productivity of wheat and soybean genotypes. - Physiol. Plantarum 145: 369-383.

[2] Allahverdiyev, T., Jahangirov, A., Talai, J., Huseynova, I. (2018): Dry matter remobilization, yield and yield components of durum (Triticum durum Desf.) and bread (Triticum aestivum L.) wheat genotypes under drought stress. - Pak. J. Bot. 50: 17451751.

[3] Arduini, I., Masoni, A., Ercoli, L., Mariotti, M. (2006): Grain yield, and dry mater and nitrogen accumulation and remobilization durum wheat as affected by variety and seeding rate. - Eur. J. Agron. 25: 309-318.

[4] Blum, A., Pnuel, Y. (1998): Physiological attributes associated with drought resistance of wheat cultivars in a Mediterranean environment. - Australian Journal of Agricultural Research 41: 799-810.

[5] Chekich, C. (2007): Investigation of the physiological parameters which may be the criteria of selection for the reproduction of drought resistant wheat (Triticum aestivum L.). - PhD Thesis, Ankara (in Turkish).

[6] Del Pozo, A., Yanez, A., Matus, I. A., Tapia, G., Castillo, D., Sanches-Jardon, L., Araus, J. L. (2016): Physiological traits associated with wheat yield potential and performance under water-stress in a Mediterranean environment. - Front. Plant Sci. https://doi.org/10.3389/fpls.2016.00987.

[7] Dordas, C. (2012): Variation in dry matter and nitrogen accumulation and remobilization in barley as affected by fertilization, cultivar, and source-sink relations. - Eur. J. Agron. 37: 31-42.

[8] Gupta,P. K., Balyan, H. S., Gahlaut, V. (2017): QTL analysis for drought tolerance in wheat: present status and future possibilities. - Agronomy 7:1-21.

[9] Jahangirov, A. A. (1987): Products of photosynthesis and peculiarities their unitilation in wheat plants with various grain yuild. - PhD Thesis in Biology, Baku.

[10] Kalayci, M., Ozbek, V., Chekich, C., Ekiz, H., Keser, M., Altay, F. (1998): Determination of drought resistant wheat genotypes in Central Anatolia conditions and development of morphological and physiological parameters. - Final Report of Tübitak Research Project, Eskishehir (in Turkish).

[11] Moussa, H. R., Abdel-Aziz, S. M. (2008): Comparative response of drought tolerant and drought sensitive maize genotypes to water stress. - Australian J. Crop Science 1: 31-36. 
[12] Mwadzingeni, L., Shimelis, H, Dube, E., Laing, M. D., Tsilo, T. J. (2016): Breeding wheat for drought tolerance: progress and technologies. - Journal of Integrative Agriculture 15: 935-943.

[13] Rampino, P., Pataleo, S., Gerardi, C., Perotta, C. (2006): Drought stress responses in wheat: physiological and molecular analysis of resistant and sensitive genotypes. - Plant Cell Environment 29: 2143-2152.

[14] Reynolds, M. P., Skovmand. B., Trethowan, R., Pfeiffer, W. (1999): Evaluating a Conceptual Model for Drought Tolerance. - In: Ribaut, J.-M., Poland, D. (eds.) Molecular Approaches for the Genetic Improvement of Cereals for Stable Production in Water-Limited Environments. A Strategic Planning Workshop Held at CIMMYT. CIMMYT, Mexico, El Batan, DF.

[15] Yang, J., Sears, R. G., Gill, B. S., Paulsen, G. M. (2002): Genetic differences in utilization of assimilate sources during maturation of wheat under chronic heat and heat shock stresses. - Euphytica 125: 179-188.

[16] Zamani, M. M., Nabpour, M. Meskarbashee, M. (2014): Stem water-soluble carbohydrate remobilization in wheat under heat stress during the grain filling. - Int. J. Agric. Biology 16: 401-405.

[17] Zhu, J. K. (2002): Salt and drought stress signal transduction in plants. - Annu. Rev. Plant Biology 53: 247-273. 